\title{
Study on Aesthetic Value of Folk Wood Paintings Yuan Wang ${ }^{1, a}$ \\ ${ }^{1}$ Xijing University, Xi'an, Shaanxi, 710123 \\ a email
}

Keywords: Folk Wood Paintings, Aesthetic Value, Artistic Characteristics, Folk Tradition

\begin{abstract}
Our long history and many forms of artistic expression is unique in the world, as part of our folk woodcut art treasures in the folk art is an important component. From the content, subject matter, carving skills, etc., to a certain extent, it reflects changes in the thoughts and feelings of folk art, moral values, religious beliefs and their development context. From the historical origins and history of the development of folk paintings, expand the aesthetic value of folk wood paintings of analysis.
\end{abstract}

\section{Introduction}

Origin of folk woodcut development of the more distant, the Chinese folk art treasures, is now the focal point of many civil research scholar. On the origin of folk woodcuts, many say is in the Qin and Han times, but some say that is described in the Sui and Tang dynasties, these have yet to be verified. The most famous folk woodcut place should be at the Yangliuqing Tianjin, Mianzhu of Sichuan, Shaanxi Fengxiang, etc., these are the most famous local wood paintings, reflect the situation in the region live. Various parts of the woodcut has its own characteristics, can not be generalized, to be classified discussions. Folk wood paintings has high research value, gained recognition folklore studies scholars.

\section{The Historical Origins of Folk Woodblock New Year Pictures}

New Year in Chinese traditional folk customs, is the Chinese New Year (Spring Festival) when pasted painting. Spring Festival is the traditional customs of the Chinese people, on behalf of the new year is coming, every family in the New Year will be to clean their own houses in order to start a new meaning. This time will be at home in the bedroom, curtains, door upper range to put new pictures, one is moral new beginning, and secondly pray God-given happiness to avoid disaster and misfortune. These are the good wishes of the people living these wishes to promote the development of folk wood paintings, and promote the constant progress of technology folk wood paintings.

There are documented in ancient books, legends in ancient times, God has called tea, Yu Lei two brothers, special supervision ghosts, demons harmful found tied up to feed the tigers. God tea, Yu Lei guardian can make this house secure. Then the Yellow Emperor on the portal Videos God tea, Yu barrier to prevent the use of like a ghost. This myth is later "keeper" Videos reason produced. It is said that the emperor had ordered the Tang Dynasty Wu Daozi painting Zhong Kui, and points out the inscription affixed to hang Minister rewarded with the provision of a ghost. Song appears engraving technology, the woodblock New Year pictures to provide technical production conditions, promote the continuous development of the New Year. With the New Year widespread, its content and functionality has been continuously enriched. To the Qing Dynasty, paintings developed to its peak. From the initial character as evil exorcism recorded, gradually added good luck, more children, more life, a kind of doll ladies theme, which also has the expression of good will in the new year, as well as landscaping features environment. At the same time, there have been paintings express the farmers themselves in real life and folklore, story content, so the New Year with a rich cultural life, the role of dissemination of knowledge. Wood paintings is a product of an era, but it is integrated folk art. 
Compared to the official New Year folk paintings in there containing the common people of life's most pristine pledge. Wood paintings are based on the basis of the development of the New Year, more mature than the style paintings, painting characters simple, natural. Simple and concise expression of the common people the most simple desires.

Song when there is sculpture, which greatly promoted the development of folk woodcut, strong sense of color in the Tang Dynasty, and a good atmosphere to promote the folk art of wood paintings show content, artistic form, color sense and so rich and varied, consistent with the public vision to give public recognition.

\section{The History of Folk Woodcut New Year}

Paintings produced from nature worship thoughts of people, in the natural thawing ideological change of man, as the state enhanced human ideas, mostly paintings is transformed from a subjective and objective ideas for physical worship, not first as an ornamental, but there is a belief.

When folk paintings of the Tang Dynasty in the printing technology has been mature development and popularization of the Song Dynasty, when the production process more and more mature wood paintings, paintings expanded content of the performance. From the performance of the future meaning to describe the phenomenon of everyday life, greatly promoted the wood paintings are spread in the folk. Tang Dynasty is the peak period of Chinese art, an active arts scene makes this wood paintings art vector has been continuously improved, especially in woodblock printing chromatograph technology maturity to develop enlarged pictures of art forms and manifestations.

New Year's themes varied, in the original technology to increase the drama, the novel, the story and portray the late folk life etc. generated content. In the form of performance is also more and more rich and varied, from the meticulous re-color engraving technology to become, or is printed Banke half. These technologies mature, the development of modern technology, changes show up is not the same pattern, the charm of art presented, in various ways, wood paintings of realistic shape, can even do real results, greatly promote promotion wood paintings, which will help the common people to accept.

Ming and Qing dynasties, when a market for wood paintings wood paintings With technical maturity extended to the general population of people in general wood paintings workshops constantly open up sales market continued to expand, introducing elements of Western painting, enriching the artistic expressions of the New Year. However, due to the Qing government of corruption and incompetence, leading to the country wide open, the invasion of foreign forces, domestic instability, so that the traditional wood paintings market has been a strong impact, some of the lost art of carving, the intrusion of foreign cultures, and wood paintings market integration of new elements, the reaction of new things, new landscapes, for example, against the powers of aggression, promoted patriotic "female school speech team plans," "victory Red", etc., have to reflect the new things, new landscapes "Shanghai Railway Station" "quit eating opium" and so on. These are the product of the times, it is the most realistic folk art of wood paintings.

Republic of China, with the invasion of foreign culture, with new promotional model, in order to adapt foreign technology and business, woodcuts became advertising carrier, China's meticulous re-color painting and Western rub carbon watercolor Combined. "Some parts" brand New Year is widely spread in the carrier civil advertising, the traditional wood paintings combine to produce the current situation at the time of the change curve.

Folk paintings is the production process needs to draw up papers, the papers will be carved in wood, or outline the contours of a pen to fill to complete, in the absence of the machine before the introduction of China, are handmade, so production inefficient, but with advances in technology, the production of wood paintings folk gradually been replaced by mechanization, wood paintings withdrew from the present stage of history, new things to replace old things.

Importance of world cultural heritage, the production process has become a folk wood paintings of factors related to the government and civil society attention of researchers, folk wood paintings because of their high artistic value, it is people pay attention to it, there are a lot of folk wood 
paintings research institutions.

\section{The Aesthetic Value of Folk Woodcut New Year Paintings Inquiry}

In the form of folk art performance varied, wood paintings are one of them, along with changes in folk culture and turn centuries, folk genre in the form of diverse wood paintings, genre and more. Wood paintings are manifestations of mind people living wishes, this folk art style are inseparable, wood paintings folk themes and people's customs, religious beliefs inseparable.

Genre mainly divided into two categories, one is painted statues, such as the portrait of God in the world inside the main room, on a person's moral guardian, avoid evil alien invasion, these contain Vesta, couplet, couplet, granary Videos ; the other is the keeper of the class, the type of keeper lot, this custom from the Tang Dynasty, goalkeeper painting, generals lifelike image, the implication is the guardian of the family's safety, the evil ghost from external invasion. Miscellaneous door after entering the door began to close things, such as the door is attached to the newlyweds "angel has ever been," "even Takako", meaning that the offspring; the door is affixed to the elderly " birthday "," Songhe sickness ", wishing the elderly can live longer.

Folk wood paintings are based on the trend of the times, constantly in the process of artistic personnel improvement and innovation, gradually formed a mature art, rough lines, bright colors, showing strong emotion. Form fit times the performance, with high artistic value.

Folk wood paintings reflect the state of people's lives for some time, with distinctive local characteristics and folk characteristics. On the way artistic performance trends and other changes in the works is a big difference, such as Tianjin Yangliuqing "Swiss sketch" (works of the early Qing Dynasty), drawn from the folk myths and legends of the White Snake. Painting handsome characters, each with dynamic posture changes, elegant color harmony and beautiful. Folk wood paintings manifested whole idea can be close to people's lives.

Folk wood paintings constitute most of them are well-balanced and full of artistic effect, the most for the level of distinct, primary and secondary orderly. Performance of the content of the compact. For example, correspond to each other goalkeeper is solemn and serious, contour clearly increased expression. There is a North-South differences on pictures colors. North hue is the color of strong focus on the main color tone is red. Green, yellow, purple, blue; and pay attention to the color of the South is gentle beauty of color, most of the use of light green, light blue, pink and other colors. And landscapes and buildings south of the region constitutes the symbol. Wood paintings in most uses exaggerated use of color, such as the big red horse, big cock. Even the color of the pig, but also adds a colorful pattern. Presented whole, unique colors and decorative arts atmosphere.

Consummate skill composition and human folk folk art is inseparable from wood paintings, exquisite sculptures, can be vivid unfolded state of people's lives, reflecting the full character.

Most are folk art reflects the state of people's lives, people are expressing the desire to pursue a happy life, for the future of the Message. Folk wood paintings will join the human factors element of nature, thought the overall theme is the worship of nature gods and worship together, extended best wishes for the future. Folk wood paintings is an expression of hope for people living, manifested ideological content and themes are very close to people's lives.

Case folk wood paintings show the life of the common people, rely on the form of folk art performance, mainly with the traditional pattern, into the era of literati painting, and is to join the Western painting characteristics. Its essence, discard the dross. Use of woodblock printing technology, innovation specific styles and genres.

Folk wood paintings often Songhe sickness, many happy returns as a symbol of longevity; paintings often used to describe a couple of mandarin ducks; desire with beauty, doll image symbol of a happy family and the descendants of the people healthy growth. New Year symbol of good luck, on behalf of the people hope for the future.

\section{Conclusion}

Folk wood paintings are Chinese folk culture in an integral and important part of the art world at 
home and abroad deserve attention. Folk Woodcut New Year has a unique artistic value, reflects a period of population living conditions. Many high value folk woodcut giant sociology, cultural studies, history, drama, etc., is a Chinese folk art, can not be missing treasure, especially in the era of information technology is not the development of civil society must be able to wood paintings extent, the impact on people's thinking so far are cultural treasures. We should pay attention to the protection of folk art, passed down to allow these arts, government and the community should pay attention to.

\section{References}

[1] Yi Yudan. aesthetic value Henan zhuxianzhen folk wood paintings of [J]. reviews of the novel, 2010 (S1):. 266-268.

[2] Liu Yi. On Chinese New Year's traditional folk theme and theme image [D]. Hebei Normal University, 2010.

[3] Zhang Xiaofei. Folk paintings and graphic design visual language studies [D]. convergence of Hunan Normal University, 2008.

[4] Li Ran. Aesthetic features Yangjiabu wood paintings of [J]. Science Review, 2016 (4).

[5] Sun Xiaohua. zhuxianzhen wood paintings color Characteristics [J]. literary life • Literary Theory, 2013 (8): 164-164.

[6] Chen Ke. Henan folk art aesthetic value analysis [J]. fine arts, 2005 (9): 25-25.

[7] Xu Xiansheng, Xu Junjie, Zhangzhou. Fujian folk wood paintings potential market analysis [J]. Oriental Art, 2006 (17): 120-123.

[8] Nima Wangzin. Traditional Folk art Inheritance and Protection policy - Kaifeng zhuxianzhen wood paintings Inheritance Strategy of [J]. family of nations, 2016 (1). 